\title{
Experiences of parents of children with intellectual disabilities in the Ashanti Region of Ghana
}

\author{
Eric Badu \\ Sightsavers International
}

\begin{abstract}
Parents of children with intellectual disabilities could experience difficulties associated with their care. Yet, insight into individual experiences is inadequate to guide effective responses to the needs of parents and their sons and daughters with intellectual disability. This study sought to explore the experiences of parents of children with intellectual disability with the aim of making these experiences visible to guide the design and provision of support services for the parents and their children. In-depth interviews were conducted with 20 parents of children with intellectual disability between the ages of 4 and 15 years residing in the Ashanti Region of Ghana. Data were analyzed using qualitative content analysis to explore themes that describe the experiences of the parents. The study found that parents of intellectually disabled children encounter challenges looking after their children due to the negative perceptions associated with having such children. Financial costs and managing behavioral challenges of intellectually disabled children were also major sources of stressors for parents. Although informal support and assurances from professionals alleviated parental stress and gave them some hope about the future of their children, these support services seem inadequate. A more structured support programme that includes financial empowerment of the parents and recognizes the importance of early detection and intervention practices is needed.
\end{abstract}

Keywords: Intellectual disability, parents, caregivers, support services, health professionals

Intellectual disability is typically characterized by substantial limitations in intellectual functioning and adaptive behavior. Children with intellectual disability experience developmental delay, which may cause obstruction in their conceptual, social, practical and personal life skills (Schalock, Luckasson, Shogren, et al. 2007). Although children with intellectual disability may acquire some skills through parental intervention, the skills acquired may be inadequate to perform functions expected of children of their age. Consequently, a large number of children with intellectual disability have developmental and behavioral challenges, which are major stressors for parents (Floyd \& Gallagher, 1997).

Studies have shown that there is an association between parental distress and caring for children with developmental cognitive delays (Cramm \& Nieboer, 2011; Khamis, 2011). The distress parents go through caring for children with developmental delays may be linked to the presence of uncompromised behavior in such children. Parents need to manage the grief and "loss" of not having an "ideal" or "perfect" child, when they have a child with intellectual disability. They also need to deal with problems associated with the behaviour, conduct and adaptive skills of children with intellectual disability; all this can be strenuous, burdensome, and stressful for parents (Boss, 1999; Heward, 2003; Gallagher et al., 2008). For example, children with cognitive impairment associated with autism may exhibit severe behaviour

Corresponding Author: Eric Badu (badu3eric@gmail.com) 
problems including physical aggression, unusual sleeping pattern, self-injury behavior, excessive physical activities and loud verbalizations. These behavior issues demand constant surveillance from the parents, which can have direct consequences, especially for single parents (Attwood, 2003, Veeraraghavan, 2006; Sanders and Morgan, 2008). Parents may experience stress caused by the extra efforts required to manage the child's behavior. Lack of financial resources can also lead to stress and depression, especially when parents spend more time on caregiving instead of working (Hastings \& Beck, 2004; Hauser-Cram, et al. 2001). This experiences can result in social isolation which may further compound stressors.

In Ghana, as in many African societies, children are cherished for several reasons. Children are a status symbol who ensure the continuity of the linage and act as social security for their parents during old age. For these reasons, bearing children is required for couples and the ultimate goal of marriage. Childlessness is the greatest misfortune that can befall a couple and can lead to divorce (Sarpong, 1974; Obi, 2004; Oppong, 2003). Sarpong (1974) mentioned that "the contempt in which childless couples are held in many parts of Ghana is to be explained against the background of the importance attached to maternity and paternity" (p. 69).

In Ghanaian traditional society, disability is perceived as the result of a curse, punishment for sins committed by persons with disabilities or their family members or the result of witchcraft, magic or sorcery (Agbenyega, 2003; Slikker, 2009; Kassah, 2008). Thus, although children are cherished in Ghana, only children considered "normal" are accepted in traditional society. Parents, especially mothers, of children who have manifestation of any "abnormality" such as behavioral or physical disorders may experience stigma, fear, blame, and social rejection (Gona, Mung'ala-Odera, Newton \& Hartley, 2011). To safeguard against giving birth to a child with disabilities, pregnant women undergo various rituals and taboos. For instance, pregnant women are not allowed to eat eggs for fear that the child might acquire hydrocephalus (Ocloo et al., 2002). Parents cautiously take measures during pregnancy to ensure that they give birth to a child who will be cherished and accepted by the immediate family and the society. This cultural expectation enables pregnant women to receive full support and protection from their partners and family members in order to give birth to a child who will be recognized and otherwise considered normal. Moreover, because parents have expectation of receiving support from their children when they are old, their happiness from having a child may diminish when they realized that the child will be "unproductive" and would need support from them instead. Children born with defect such as physical deformities may therefore be kept out of public view or killed at birth because of the shame and/or misfortune brought on the parents (Agbenyega, 2003; Avoke, 2001; Bleek \& AsanteDarko, 1986; Baffoe, 2013).

Due to the stress parents with intellectually disabled children experience, adequate support is required to overcome the challenges the children pose for them. United Nations Children Fund (UNICEF), for example, encourages countries to support families and caregivers of children with disabilities through professional training and financial assistance to improve on the quality of life for both parents and children (UNICEF, 2007). However, information on the experiences of Ghanaian parents of children with intellectual disability needed to inform policy making is scarce. Current research pertaining to disability seems to focus largely on 'bread and butter' issues including cash transfers, donation, financial and daily lives, relegating to the background experiences that parents go through caring for their ID child which may include stress, financial burden and isolation. Understanding the experiences of parents is crucial for designing support services for parents and their children. This study examined the experiences of parents of children with intellectual disability, with the aim of making these experiences visible so that appropriate support services can be designed to support parents and caregivers. 


\section{Method}

\section{Study design and type}

This is exploratory study and utilized qualitative data collection methods to elicit information on the caring experiences of parents of children with intellectual disability. Qualitative methodology seeks to provide in-depth information about subjective experiences (Creswell, 2009). The sensitive nature of recounting the subjective experiences of parents of children with intellectual disability requires the use of qualitative methods. This study was conducted in the Ashanti Region of Ghana from 2013 to 2014.

\section{Study population}

The target population for this study were parents and caregivers of intellectually disabled sons and daughters aged $4-15$ years residing in the Ashanti region. Parents were selected based on certain characteristics that their children with intellectual disability possessed. Their child had to be between $4-15$ years and must have been diagnosed with intellectual disability by a certified medical practitioner. There were two categories of parents in the target group: those whose children were attending special schools, such as schools for the intellectually disabled, and those whose children were not in school.

\section{Sampling technique and sample size}

Convenience sampling methods were used to select participants who were parents or caregivers of children with intellectual disability. The recruitment of participants was done through initial contacts with institutions in the study area that provide services to children with intellectual disability to assist in locating parents. These institutions were Garden City Special School for the Intellectually Disabled in Kumasi, the capital of Ashanti Region, the Department of Social Welfare, Disabled People Organizations and parents support groups. Prior to their enrolment, introductory letters were sent to the prospective participants explaining eligibility requirements, their role in the study, and an invitation to participate in the study. The researchers then collated names of all participants who accepted to participate in the study, and met them on a preset date to go through screening and the informed consent process. On the screening day, those who qualified to participate were recruited after signing the informed consent form. A total of 20 parents or caregivers, made up of 10 parents or caregivers whose children were in school and 10 parents or caregivers whose children were out of school at the time of the study, were enrolled in the study.

\section{Ethical consideration}

A written approval was obtained from the Garden City Special School for the Intellectually Disabled prior to the data collection. The Committee for Human Research Publication and Ethics at Kwame Nkrumah University of Science and Technology (KNUST) reviewed and approved the study protocols prior to the implementation of the study. Prospective participants were taken through the consent process and provided consent before participating in the study.

\section{Data collection techniques and tools}

The data were collected over a period of one month between April and May 2014. An interview guide was developed to collect information on the following issues from parents: initial experiences of parents when they realized they had given birth to an intellectually disabled child, challenges parents with intellectually disabled children encounter, and support services available to them. The information was collected by conducting in-depth interview with parents and caregivers with additional probing questions. Apart from these major topic points, demographic information, such as, age, gender, marital status, religion, occupation, income level, and level of education were collected using a demographic form. The interview guide was written in English, but the interviews were conducted in Twi, the indigenous language of the people in Ashanti Regions. Two research assistants, who are 
indigenes and fluent in the local language, conducted the interview. Each interview section took approximately one hour and a voice recorder was used to record response to the questions with permission from the participants. To ensure rigor in the data collected, the researchers monitored the interview process by debriefing after each interview to ensure consistency in the interview.

\section{Data management and analysis}

All audio recordings were transcribed verbatim with the help of the two research assistants. Each interview was transcribed separately in order to differentiate what each participant said. Each assistant transcribed the audio recordings separately into text format in English. The researchers, with the two transcribers, read through the transcribed data several times to reconcile difference in the translation and transcription. The final transcripts were read several times to identity concepts and broad ideas that are related to the objectives of the study. These concepts and broad ideas were given alphabetical codes. Concepts and ideas that are related in each interview were given the same alphabetical codes. All concepts and statements that were similar or have similar meanings from all the individual interviews were grouped under one theme.

\section{Results}

\section{Participant characteristics}

Table 1 summarizes the characteristics of study participants. The majority (90\%) of the parents and caregivers were females. In terms of marital status, $65 \%$ were married while the remaining were either single (5\%), cohabiting $(5 \%)$, widows $(15 \%)$ or divorced $(10 \%)$. With respect to the relationship of the caregiver to the child, $75 \%$ were the biological parents of the children while $15 \%$ were not. The highest educational attainment of the participants was tertiary education (5\%) and the lowest was primary education (20\%). Most of the parents $(95 \%)$ were employed, with trading (60\%) being their main occupation. However, of the 20 participants, only three (15\%) were able to estimate their monthly income; the highest amount a parent/caregiver was earning was GHC1000 a month and the lowest was GHC 250 (US\$ 66), the average income being GHC 516.67 (US\$ 136).

Table 1 Demographic characteristic of participants

\begin{tabular}{lcc}
\hline Variable & N & Percentage \\
\hline Gender & 2 & 10 \\
Male & 18 & 90 \\
Female & & 5 \\
Education & 1 & 35 \\
Tertiary & 7 & 35 \\
SSS/Middle School & 7 & 20 \\
JHS & 4 & 5 \\
Primary & 1 & 65 \\
None & & 5 \\
Marital status & 13 & 15 \\
Married & 1 & 10 \\
Single & 3 & 5 \\
Widow & 2 & \\
Divorce & 1 & 5 \\
Co-habitation & & 60 \\
Employment status & 10 \\
Waged employment & 1 & 20 \\
Trading & 12 & 5 \\
Farming & 2 & \\
Unemployed & 4 & 1 \\
\hline
\end{tabular}




\begin{tabular}{|c|c|c|}
\hline \multicolumn{3}{|l|}{ Relationship to the child } \\
\hline Biological & 17 & 75 \\
\hline Caregiver & 3 & 15 \\
\hline
\end{tabular}

\section{Identifying condition and reaction of parents}

Most of the parents (85\%) said they learned of their child's diagnosis when the children were two years and above with only a few parents indicating the condition was identified a few days after birth. The most common signs that informed parents that something was wrong or different with their children was the detection of unusual physical characteristics or/and the inability of the children to engage in typical milestone activities expected of children of their age, such as, crying, walking or talking.

According to the participants, they became suspicious of their children's condition by observing their atypical behaviour or unusual physical characteristics. The parents' first action was to consult health professionals such as doctors. If it was confirmed that their child had an intellectual disability, they expressed surprise, disbelief and became confused. Some of them resorted to self-blaming and denial. As one parent explained:

When I detected that my child has an unusual colour I didn't understand. I consulted a doctor and I was told that my child has intellectual disability. I didn't believe it and it wasn't easy for me to just accept it when the Doctor told me. I was confused and didn't know what to do. I thought it was a curse of my bad deeds I did to a fellow human or God [Interview 5].

Although intellectual disability is not curable, many parents did not give up after the confirmation that the child has intellectual disability. They reportedly tried various remedies including consulting medical and native doctors, prayer camps, and herbalists. For instance, one biological mother said that, "I was thinking about how to get a doctor to heal the child's condition which ended me at the hospitals, prayer camps and traditional healing centres" while another parent resorted to "thinking about it, fasting and praying" for a remedy. Some parents said they had hoped that their children's condition would improve. For example, a parent said she was "relief and tried to cope with the situation when a doctor assured me that his condition will change when he grows. He cooled down my worries." However, many of the participants said they were uncertain and worried about the future of their children. Several participants were unhappy with the attitude of male partners for abandoning them and their children. Two parents summarized their experiences:

My husband also left me with my three children upon the realization of an intellectually disabled child. My first born would have to go to "galamsey" [small scale mining] while the second one also went for shoe shine in order to get money to support the family [Interview 3].

I became devastated as people used to laugh at me that I have given birth to an animal. I used to cry in the night alone. My husband even threw my belongings out and I had to pass the night outside with the child. Because of these, I sought for cure from native doctors to prayer camps and hospitals. He is my child and I can't abandon or kill him [Interview 16].

\section{Sources of stressors}

The parents reported that caring for an intellectually disabled child involved a lot of stress. Stress as reported by the parents was associated with the worry or anxiety of caring for the intellectually disabled child alone; that is, one parent having to deal with the numerous physical, behavioural and developmental issues associated with intellectually disabled 
children, such as providing personal skills, for example, toileting, eating, bathing and helping the females during menstruation. A parent narrated her experience:

It is very difficult to care for an intellectually disabled child particularly when you are alone. I really experience stress out of caring for him together with other two children. The situation was serious, particularly when they were young. There is always misunderstanding between me and their father for not helping me in the daily activities. I always quarrel with his father for leaving the entire task on me alone [Interview 2].

Another source of stress was managing the negative attitudes of community members. Many of the parents complained of the attitude of their neighbours towards them and their intellectually disabled children, which made it difficult for them to interact with their neighbours and also participate in community activities. The following comments illustrate the experiences of some parents:

In my community, they laugh at me whenever I am walking with my intellectually disabled child. They pretend to show up when they are with me but immediately I leave, then they insult me and look down upon me. Some tell me I have given birth to an animal and I should go and throw my child away by saying "nawonkogya no kwan" [which means I should eliminate my child from this earth] [interview16].

It was difficult for me to socialize with people in my community. I was not looking good at all because of the discrimination by community members. I always cried and hid myself from people and stayed in my house but it is now better because ever since she went to school, she has changed' [Interview 19].

Managing one's job while caring for their intellectually disabled children could be very stressful for parents, especially single parents and this seemed to have affected the performance of some parents. For example, a parent indicated that she was "unable to perform her jobs effectively because of caring for an intellectually disabled child as caring for the child required a lot of time and meeting the time at the workplace." Another participant recounted how caring for her intellectually disabled child affected her work and income:

When I am with her, efficiency towards my work is generally lower than when she is with the grandmother. Taking care of her really affects my finance and time I used on other things. One disturbing thing is that I always have to hire a car when I want to take her somewhere since she cannot walk [Interview 1].

Caring for a child with intellectual disability requires constant supervision, which can be time consuming and demands a lot of patience from the carer. Combining caring of the child with one's daily activities can therefore be frustrating and stressful. As a result, some of the parents said they employed caregivers to assist them during the day, while those who could not employ caregivers had to give up their own work completely.

The stigma associated with having a child with intellectual disability even extended to the parents' future work prospects or current workplace as employers were unwilling to employ parents who have children with intellectual disability. As one parent stated, "Whenever I go and search for employment, they turn me down when they see my child." Those who were self-employed claimed their apprentices left them because of their intellectually disabled children.

I am a hairdresser and I used to have a lot of apprentice. However, when I gave birth to a child with an intellectual disability, they have all left and he wouldn't go to anybody else. I have to carry him, feed, bath and cloth him [Interview 5]. 
The experiences indicated a number of stresses are associated with managing the behavior and developmental challenges of their intellectually disabled children while also coping with society's negative attitudes and stigma and trying to maintain employment and community participation.

\section{Discussion}

Children with intellectual disability experience substantial limitations in intellectual and functional abilities which obstruct their social, practical and personal life skills (Schalock, et al. 2007). As result, it is not surprising that parents with intellectually disabled children go through a lot of stressful experiences associated with their care. The finding that parents of children with intellectual disability were unhappy about the condition of their children is natural and expected. This finding corroborates previous studies on attitude towards children with disabilities in Ghana; studies have found that children born with disabilities in Ghana are perceived as violating traditional norms, and so, such children and their families are stigmatized and taunted - some are even killed (Bleek \& Asante-Darko, 1986; Avoke, 2001) Agbenyega, 2003).

The finding indicating that parents of children with intellectual disability experienced stress for taking care of children with intellectual disability also corroborates findings by Cramm \& Nieboer (2011) and Khamis (2007). These studies have discovered an association between parental distress and caring of children with developmental challenges. However, it is worthwhile noting that parental stress may not necessarily always arise from the behavioral challenges of the child and negative attitudes of society. The feeling of helplessness can be a major source of stress for all parents. Boss (1999) states that perceiving a family member as present when he or she is psychologically absent "can make people feel helpless and thus more prone to depression, anxiety, and relationship conflicts." (p. 7)

The finding that parents expressed uncertainty about the condition of their children has several possible interpretations and imprecations. Firstly, it may reflect a conflict between perceptions about disability internalized by individuals on one hand, and the relationship that the parents (especially mothers) had established with their children even before they were born, on the other. That is, mothers seemed to have been torn between playing the rules of society and performing their motherly roles simultaneously, creating uncertainty about which role surpasses the other. These motherly roles and values probably held mothers back while fathers deserted. Secondly, the uncertainty may arise from what Boss (1999) called ambiguous loss. Ambiguous loss is the grief or distress arising from a loss in which there is uncertainty, doubt or confusion about the person or relationship; that is, a loss that is unclear. With ambiguous loss, the person "may be perceived as physically present but psychologically absent" [emphasis in the original] (Boss, 1999, p. 9).

In the case of death, one does not normally expect the return of their loss loved one. Performing the necessary rituals marks the end of the grief. The rituals inform family members that all is over and a new relationship begins (Boss, 1999). However, in the case of having a son or daughter with intellectual disability, there is no clear-cut loss. Although the individual with the condition is physically alive and does not mean he/she is absent psychologically. In traditional society where individuals are expected to perform certain roles, the intellectually disabled child could also be absent socially because he or she may not be able to perform the expected roles and his or her social presence may diminish. Parents are therefore likely to have doubt and uncertainty (or confused) about the capabilities of the child and the kind of loss they are dealing with. It is also worthy to note that parents were probably aware that intellectual disability is irreversible, but they also had some hope that the child's condition may change - parents got assurances from health professionals that gave them 
some hope (anecdotal stories about miraculously healing are also abound in Ghana). This may be a source of confusion for some of the parents.

Lastly, although parents perceived there were claims and suggestions from community and family members, this did not influence them to kill their intellectually disabled children. In a related studies, several authors have cited cases of children with disabilities being killed by their families due to similar stereotypes by friends and the community (Baffoe, 2013; Obi, 2004; Oppong, 2003). Although killing the child may shorten the grief of the parents, it is a dilemma that may create confusion or uncertainty for some parents. Some parents who are presented with this paradox - either to shorten their grief by eliminating the child completely or lengthen their grief by allowing the child to live.

Though some parents did not believe it when their children were first confirmed to have intellectual disability, the study does not provide any clear reason why parents did not believe this news by health professionals. In traditional society for example, a lot of activities such as wearing talismans, drinking herbal concoctions and using "holy" oil are done to protect the pregnant women and the fetus. Pregnant women also observe taboos to ensure safe childbirth delivery and to protect the child (Sarpong, 1974). Apart from these traditional practices, modern antennal care and fetal scanning are supposed to identify any "disorders" in the child. Consequently, if after birth, the child has "defects", mothers would express disbelief if they had observed all the rules during pregnancy. Those who thought they had not observed the rules properly may resort to self-blaming.

\section{Limitations of the study}

The study was limited to a section of parents of children with intellectual disability in one region out of the 10 regions in Ghana, yet the findings has provided useful information that could be used to inform policy responses and advocacy for parents and children with ID in the country. The data were limited to the experiences of parents and did not include the views of service providers like doctors, special educators, social workers and broader stakeholders groups. However, the findings on parents' experiences are relevant to the design of support services for children with ID in Ghana. Further research with parents including in other regions and with other stakeholder groups is required. . Future studies should consider how parental characteristics for example, education, occupation, sex of the child, and birth order may influence parental experience.

\section{Implications}

Findings from the study point to the need for effective screening of pregnancies and newly born children. Early identification of developmental disorders in children is critical for the well-being of the children and their families. If developmental disorders in children are detected early, measures could be taken to prevent further developmental delays that could intensify the condition in children and also provide access to support and services that will have benefits for the child and the parents. For example, early detection, especially if it is done by health professionals and Community Based-Rehabilitation (CBR) workers can be useful to the parents as they can received early counselling and support that will enable them to cope with and manage the behavioral challenges of their children. Screening for early detection and intervention should, therefore, be one of the essential functions of any health care system (Cole \& Flexer, 2007). However, findings from the study suggest that most parents detected the condition in their children late. This suggests lapses in the screening for early detection of intellectual disabilities in children for appropriate intervention. Late detection by parents may have made it impossible for some parents to receive early support from health professionals, and this may have made coping difficult for some of them. Studies have indicated that early detection offers opportunities for appropriate intervention, which has in turn reduced the impact of stressors on families (Heward, 2003; Olsson \& Hwang, 2001; Tam \& Cheny, 2005; Tervo, 2010). Therefore, pregnant women should be encouraged to regularly attend antenatal clinics so that problems that can lead to disorders 
in babies can be detected for early intervention. In this regard, health facilities should be equipped with basic screening tools to undertake screening of pregnancies and children effectively.

The above measures should be matched by effective counseling and support services at health facilities and at the Department of Social Welfare to support parents in their grief. The availability of these services would help parents to manage their children's behavior and give them support which may help alleviate stress. Moreover, disability rights activists and Disabled People Organizations should step up efforts to advocate for the implementation of provisions of the Persons with Disability Act 715 . In particular, provisions that prohibit the use of derogatory names on persons with disabilities and the section requiring the Ministry of Health to conduct periodic screening of children should be implemented.

Financial and employment concerns were major stressors for parents in the study, most especially single parents. A social protection programme in the form of monthly allowances specifically for poor parents of children with intellectual disability to cushion their financial costs could be implemented. Alternatively, parents could be enrolled in existing social protection programmes such as the Livelihood Empowerment Against Poverty (LEAP) programme currently being implemented for poor households in Ghana. The LEAP is a social protection programme which provides cash transfer and health insurance to extremely poor household in Ghana to alleviate short-term poverty and encourage long term human capital development (Abebrese, 2012).

In addition, findings from the study suggest that enrolling children with intellectual disability in schools can reduce the pressure on parents. In view of this, efforts should be made to increase enrolment for children with disabilities generally. A vigorous campaign to reduce misconceptions about disability and increase awareness among community members and parents on the capabilities of persons with disabilities should be pursued to facilitate their social inclusion, particularly in education settings. The inclusive education programme currently being piloted in Ghana is likely to address some of the enrolment challenges for children with disabilities, but there is need for expansion in the facilities in all special schools. Enrolling the children in schools would give parents more time to engage in economic activities and offer the children opportunity to acquire daily living skills. In addition, professionals providing services for intellectually disabled children and parents, particularly special educators should be given adequate training and motivated to encourage them to work effectively with students with intellectual disability.

\section{Conclusion}

This study explored the experiences of parents of children with intellectual disability and found that parents, as usual, experienced emotional stress, social stigma, financial hardship and marital strain in taking care of their children with intellectual disability. The study has useful implications as it comes at a critical juncture when attention on issues concerning persons with disabilities and their families are gaining momentum in Ghana. The findings calls for improvements in the support service provided for parents to their children with disabilities generally, this includes recognizing the importance of designing programmes that will encourage family participation, matching services to the needs of the family, and incorporate economic empowerment into family support services.

\section{Acknowledgements}

The authors wish to thank the Garden City Special School and the Centre for Disability and Rehabilitation Studies, Kumasi for their support during the fieldwork. The authors again wish to thank all parents support group for children with intellectual disabilities especially those who participated in the study. 


\section{References}

Abebrese, J. (2012). Social Protection in Ghana: An overview of existing programmes and their prospects and challenges. Retrieved from http://library.fes.de/pdffiles/bueros/ghana/10497.pdf.

Agbenyega, J.S., 2003, The Power of labelling discourse in the construction of disability in Ghana. Educational Research, Risks and Dilemmas, 29 November 2003 to 03 December 2003. Retrieved from http://citeseerx.ist.psu.edu/viewdoc/download?rep=rep1\&type=pdf\&doi=10.1.1.214.8 974

Attwood, T. (2003). Why Does Chris Do That?: Some Suggestions Regarding the Cause and Management of the Unusual Behaviour of Children and Adults with Autism and Asperger Syndrome: AAPC Publishing.

Avoke, M. (2001). Some historical perspectives in the development of Special Education in Ghana. European Journal of Special Needs, 16, 29-40

Baffoe M. (2013), Stigmatization, discrimination and marginalization: Gateways to oppression of persons with disabilities in Ghana, West Africa. Journal of Education and Social Research, 3(1), 187-198.

Bleek, W., \& Asante-Darko, N. K. (1986). Illegal abortion in Southern Ghana: Methods, motives and consequences. Human Organization, 45(4), 333-343.

Boss, P (1999) Ambiguous loss: Learning to live with unresolved grief. Harvard University Press, Cambridge

Cole, E., and Flexer, C. (2007). Children with hearing loss: Developing listening and talking, birth to six. San Diego: Plural Publishing, Inc.

Cramm J. M. \& Nieboer A. P. (2011). Professionals' views on interprofessional stroke team functioning. International Journal of Integrated Care, 25, http://www.ijic.org/index.php/ijic/article/view/657/1377

Creswell, J. W. (2009). Research design: qualitative, quantitative and mixed methods approaches (3rd Ed.). SAGE Publications: Los Angeles, 2009.

Floyd, F. J. and Gallagher, E. M. (1997). Parental Stress, Care Demands, and Use of Support Services for School-Age Children with Disabilities and Behavior Problems. Family Caregiving for Persons with Disabilities, 46, (4), 359-371.

Gallagher, S., Phillips, A. C., Oliver, C., \& Carroll, D. (2008). Predictors of psychological morbidity in parents of children with intellectual disabilities. Journal of Pediatric psychology, 33(10), 1129-1136.

Gona, J., Mung'ala-Odera, V., Newton, C., \& Hartley, S. (2011). Caring for children with disabilities in Kilifi, Kenya: what is the carer's experience? Child: Care, Health and Development, 37(2), 175-183.

Hastings, R. P., \& Beck, A. (2004). Practitioner review: Stress intervention for parents of children with intellectual disabilities. Journal of Child Psychology and Psychiatry, 45(8), 1338-1349.

Hauser-Cram P., Warfield M. E., Shonkoff J. P., Krauss M.W., Sayer A, Upshur CC. (2001). Children with disabilities: a longitudinal study of child development and parent wellbeing. Mongr Soc Res Child Dev, 66(3), 1-26.

Heward, W. L. (2003). Exceptional Children; An Introduction to Special Education (Seventh ed.). New Jersey, United State: Pearson Education, Inc.

Kassah, A. K. (2008). Begging as work: a study of people with mobility difficulties in Accra, Ghana. Disability \& Society, 23(2). DOI:10.1080/09687590701841208

Khamis, S. (2007). The Transformative Egyptian Media Landscape: Changes, Challenges and Comparative Perspectives. International Journal of Communication, 5, 11591177.

Obi, F. B. (2004). Effective Parenting of Children with special needs. Accra, Ghana: Florence Banku Obi. 
Ocloo, M. A., Hayford, S., Agbeke, W.K., Gadabui, G., Avoke, M., \& Boison, C.I. (2002). Foundation of Special Education: The Ghanaian Perspective. Cape Coast, Ghana: Nyakod Printing Works.

Olsson, M. B., \& Hwang, C. (2001). Depression in mothers and fathers of children with intellectual disability. Journal of Intellectual Disability Research, 45(6), 535-543.

Oppong, A. M. (2003). Understanding and Effectively Educating the Special Needs Students (First ed.). Winneba, Ghana: University of Education.

Sanders, J. L., \& Morgan, S. B. (2008). Family stress and adjustment as perceived by parents of children with autism or Down syndrome: Implications for intervention. Child \& Family Behavior Therapy, 19(4), 15-32

Sarpong, P. (1974). Ghana in retrospect. Accra, Ghana: Ghana Publishing Corporation.

Shearn, J., \& Todd, S. (2000). Maternal employment and family responsibilities: The perspectives of mothers of children with intellectual disabilities. Journal of Applied Research in Intellectual Disabilities, 13(3), 109-131.

Schalock RL1, Luckasson RA, Shogren KA, Borthwick-Duffy S, Bradley V, Buntinx WH, Coulter DL, Craig EM, Gomez SC, Lachapelle Y, Reeve A, Snell ME, Spreat S, Tassé MJ, Thompson JR, Verdugo MA, Wehmeyer ML, Yeager MH (2007). The renaming of mental retardation: understanding the change to the term intellectual disability. Intellect Development Disability, 45(2), 116-24.

Slikker, J. (2009). Attitudes towards people with disabilities in Ghana. Accra, Ghana: VSO Ghana.

Tam, S.-F., \& Cheng, A. W. (2005). Self-concepts of parents with a child of school age with a severe intellectual disability. Journal of Intellectual Disabilities, 9(3), 253-268.

Tervo, R. C. (2010). Attention problems and parent-rated behavior and stress in young children at risk for developmental delay. Journal of child neurology, 25(11), 13251330.

United Nations International Children's Fund [UNICEF]. (2007). Promoting the Rights of Children with

Disabilities. Retrieved from http://www.un.org/esa/socdev/unyin/documents/children_disability_rights.pdf[Access ed 14/5/2015].

Veeraraghavan, V. (2006). Behaviour Problems in Children and Adolescents: Northern Book Centre. 